\title{
Epilepsy from Cerebral Arteriovenous Malformations
}

\author{
Richard Leblanc, William Feindel and Roméo Ethier
}

SUMMARY: Twenty-seven patients with epilepsy as the only manifestation of a cerebral AVM were seen at the MNI/MNH from 1973 to 1981. The nine females and eighteen males between the ages of fourteen and fifty-four years (Mean 25.2 years) had epilepsy for an average of 3.5 years prior to the diagnosis of AVM.

Seven patients had primarily generalized seizures, ten patients had partial seizures with complex symptoms, fourteen patients had partial seizures with elementary symptoms, and thirteen patients had secondarily generalized seizures. Although there was no history of intracranial hemorrhage, seven patients had negative hemispheric signs (hemiatrophy, hemianopia, dysphasia, hemiparesis), two had impaired mentation, and two were ataxic. The EEG, normal in ten cases, showed non-epileptiform activity in six cases, and focal epileptiform activity in eleven cases. Angiographic and/or histological examination revealed eight small (less than $2 \mathrm{~cm}$ in diameter) and nineteen large lesions. Fifteen AVMs involved the frontal lobe, ten the temporal lobe, five the parietal lobe, and one the occipital lobe. Angiography failed to demonstrate three frontal and three temporal AVMs.

Plain CT scanning demonstrated a high or low density lesion without a mass effect in sixteen cases, enlargement of the ipsilateral ventricle or Sylvian fissure in seven cases, and diffuse ventricular enlargement in three cases. CT scanning was performed after the intravenous injection of contrast material in nineteen cases and demonstrated vascular enhancement in fifteen cases and an abnormal blood vessel in six cases. Two angiographically occult AVMs demonstrated vascular enhancement with infusion CT scanning, thereby demonstrating the vascular nature of the lesion where angiography had failed to do so.

RÉSUMÉ: Nous avons vu au MNI/MNH, de 1973 à 1981, 27 patients dont l'épilepsie était la seule manifestation d'une malformation artério-veineuse cérébrale. 9 femmes et 18 hommes (de 14 à 54 ans, moyenne 25.2) avaient eu leur épilepsie pour une moyenne de 3.5 ans avant le diagnostic de la malformation.

Sept patients avaient de crises principalement généralisées, 10 patients des crises partielles avec symptômes complexes, 14 patients des crises partielles avec symptômes élémentaires et 13 patients des crises secondairement généralisées. Même sans histoire d'hémorragie intracrânienne, 7 patients d'avaient des signes hémisphériques (hémiatrophie, hémianopsie, dysphasie ou hémiparésie): 2 patients avaient une atteinte mentale et deux étaient ataxiques. L'EEG, normal chez 10 patients, démontrait une activité non-épileptique chez six et épileptique focale chez onze. L'examen angiographique et/ou histologique a révélé huit petites lésions et 19 grandes lésions. De ces malformations. 15 impliquaient le lobe frontal, 10 le lobe temporal, 5 le lobe pariétal et une le lobe occipital. L'angiographie a manqué 3 lésions frontales et 3 temporales.

La tomodensitométrie simple a démontré une lésion de haute ou de basse densité, sans effet de masse, chez 16 patients, un agrandissement du ventricule ipsilatéral ou de la fissure sylvienne chez 7 et un agrandissement ventriculaire diffus chez 3 . Chez 19 patients la tomodensitométrie fut faite après injection intraveineuse de matériel de contraste et elle démontra une potentiation du lit vasculaire dans 15 cas et un vaisseau anormal dans 6 cas. Deux malformations silencieuses à l'angiographie furent illustrées après infusion préalable à la tomodensitométrie, démontrant ainsi la nature vasculaire de la lésion alors que l'angiographie l'avait manquée.

Can. J. Neurol. Sci. 1983; 10:91-95

Epilepsy is a frequent complication of a cerebral arteriovenous malformation (AVM). At our institution, seizures are the presenting complaint in thirty-six per cent of patients with an AVM and cerebrovascular malformations account for six per cent of tumoral and vascular lesions excised for the treatment of focal epilepsy (Leblanc et al, 1979; Rasmussen 1974). Although many reports attest to the usefulness of computed tomographic (CT) scanning in the detection of surgically amenable lesions in epileptics, few address AVMs in particular (Bauer and Pallua, 1980; Bell et al, 1978; Gastaut and Gastaut, 1976; Jabbari et al, 1980; Loiseau et al, 1977; McGahan et al, 1979). In those reports specifically concerned with the CT appearance of AVMs most of the scans were obtained after the occurrence of an intracranial hemorrhage so that the predominant finding is an intracerebral hematoma or its secondary ef- fects (Hayward, 1976; Meese et al, 1976; Pressman et al, 1975; Terbrugge et al, 1977). In such cases, the location of the hematoma and the demonstration of vascular enhancement or of an abnormal blood vessel can suggest the diagnosis of an AVM as opposed to other causes of intracranial hemorrhage (Hayward, 1976; Leblanc et al, 1979). The present report reviews the clinical and investigational profile of a series of patients in whom epilepsy was the only manifestation of a cerebral AVM, and addresses the usefulness of CT scanning in the early diagnosis of these often surgically amenable lesions.

\section{ANALYSIS OF CASES}

Twenty-seven patients with epilepsy as the only manifestation of a cerebral AVM were seen at the Montreal Neurological Institute and Hospital between October, 1973 
and October, 1981. The nine females and eighteen males between the ages of fourteen and fifty-four years (mean age 25.2 years) had had a seizure disorder for an average of 3.5 years prior to the diagnosis of the AVM. Patients with Sturge-Weber disease, capillary telangiectasia, venous malformation, and cavernous hemangioma, and patients with a history of intracranial hemorrhage were excluded from this study. The AVMs are characterized as small when they measure $2 \mathrm{~cm}$ or less in diameter, and, as large when they measure more than $2 \mathrm{~cm}$ in diameter. There were eight small lesions and nineteen large ones. Sixteen patients were operated on and the diagnosis of AVM was confirmed histologically. In the other 11 patients the diagnosis was made from the characteristic findings on angiography. Only one patient had a normal angiogram and a normal CT scan. In that case, the AVM was diagnosed by histological examination of the temporal lobe removed for the surgical control of medically intractable seizures.

Seven patients had primarily generalized seizures, ten had partial seizures with complex symptoms, fourteen had partial seizures with elementary symptoms, and thirteen had secondarily generalized seizures (Table 1). The elementary symptoms exhibited were focal motor in ten cases, aphasic in two cases, somatosensory in two cases, vertiginous in two cases, and visual in one case. The complex symptoms were those classically seen in temporal lobe epilepsy, including automatism in seven cases (Feindel, 1973). The findings on physical examination are presented in Table 2. The neurological examination was normal in fourteen cases. Mild negative hemispheric signs such as hemiatrophy, dysphasia, hemianopia or hemiparesis were seen in seven cases, poor intellectual function in two cases and limb ataxia in two cases. A cranial or cervical bruit was heard in three cases. An EEG was obtained in all cases, but most were obtained with the patient on therapeutic doses of anticonvulsant medication. The EEG was normal in ten cases. Predominantly focal or diffuse non-epileptiform activity was seen in six cases, and predominantly focal epileptiform activity was seen in eleven cases.

Cerebral angiography was performed at four films per second in all cases and demonstrated the AVM in twenty-one cases. All the lesions were supratentorial and involved mainly the fronto-temporal areas, with the parietal and occipital areas involved to a lesser degree (Table 1). The AVMs were supplied by branches of the middle cerebral artery in sixteen cases, from the anterior cerebral artery in eleven cases and from the posterior cerebral artery in six cases. Three frontal lesions received some of their arterial supply from the contralateral anterior cerebral artery. Four small and two predominantly thrombosed large AVMs were not demonstrated by angiography. Three were in the frontal and three in the temporal lobe.

All the patients had a non-infused CT scan performed with an EMI head or body scanner and nineteen patients had a CT scan performed after the intravenous infusion of contrast material (Ethier et al, 1974) (Table 3). Four plain CT scans were normal but two of these demonstrated vascular enhancement with the infused study. A high density lesion without a mass effect was seen in thirteen noninfused CT scans, and a high density lesion with compression of the lateral ventricle by the angiomatous mass was seen in two plain CT scans. Signs of cerebral atrophy, seen

Table 1: Classification of Seizures and Location of the AVMs

\begin{tabular}{lccccc}
\hline \hline & & \multicolumn{4}{c}{ TYPE OF SEIZURE } \\
LOCATION & NO. OF CASES & \multicolumn{2}{c}{ PARTIAL } & GENERALIZED \\
\hline & & Elementary & Complex & Secondarily & Primarily \\
Frontal & 13 & 7 & 3 & 5 & 5 \\
Fronto-Parietal & 2 & 1 & & & 1 \\
Parietal & 2 & 2 & 7 & 6 & \\
Temporal & 8 & 3 & & 1 & 1 \\
Temporo-Parietal & 1 & 1 & 10 & 13 & 7 \\
Temporo-Occipital & 1 & 14 & 10 & & \\
& 27 & 14 & & &
\end{tabular}

Table 2: Physical Findings on Examination

\begin{tabular}{lrccc}
\hline \hline \multirow{2}{*}{ FINDING } & NO. OF & NO. OF ABNORMAL & \multicolumn{2}{c}{ SIZE OF THE AVM } \\
SMALL & CASES & PLAIN CT SCANS & SMARG \\
\hline Normal Examination & 14 & 13 & 5 & 9 \\
Cranio-Cervical Bruit & 3 & 2 & & 3 \\
Poor Intellectual Function & 2 & 2 & 3 & 2 \\
Negative Hemispheric Signs & 7 & 4 & & \\
$\quad$ Hemiatrophy & 2 & & & \\
Dysphasia & 2 & & & \\
Homonymous Hemianopia & 3 & & & \\
Facial Asymmetry & 4 & & & \\
Hemiparesis & 2 & & & \\
$\quad$ Hemi-Hyperreflexia & 2 & & & \\
Ataxia & 2 & & & \\
\hline
\end{tabular}



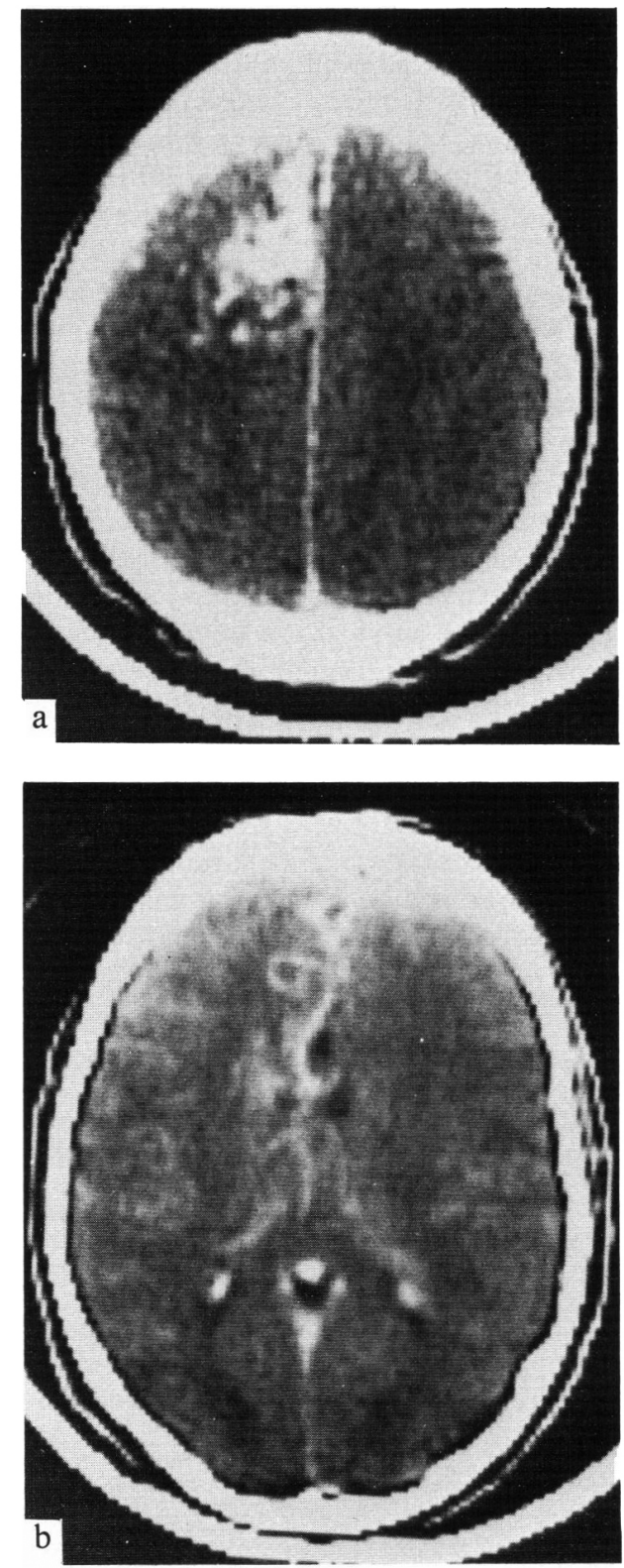

Figure 1 - CT scan demonstrating a large, enhancing high density lesion in the left frontal lobe (a), associated with an abnormal blood vessel (b), and corresponding angiogram (c), demonstrating a large arteriovenous malformation and enlarged feeding artery.

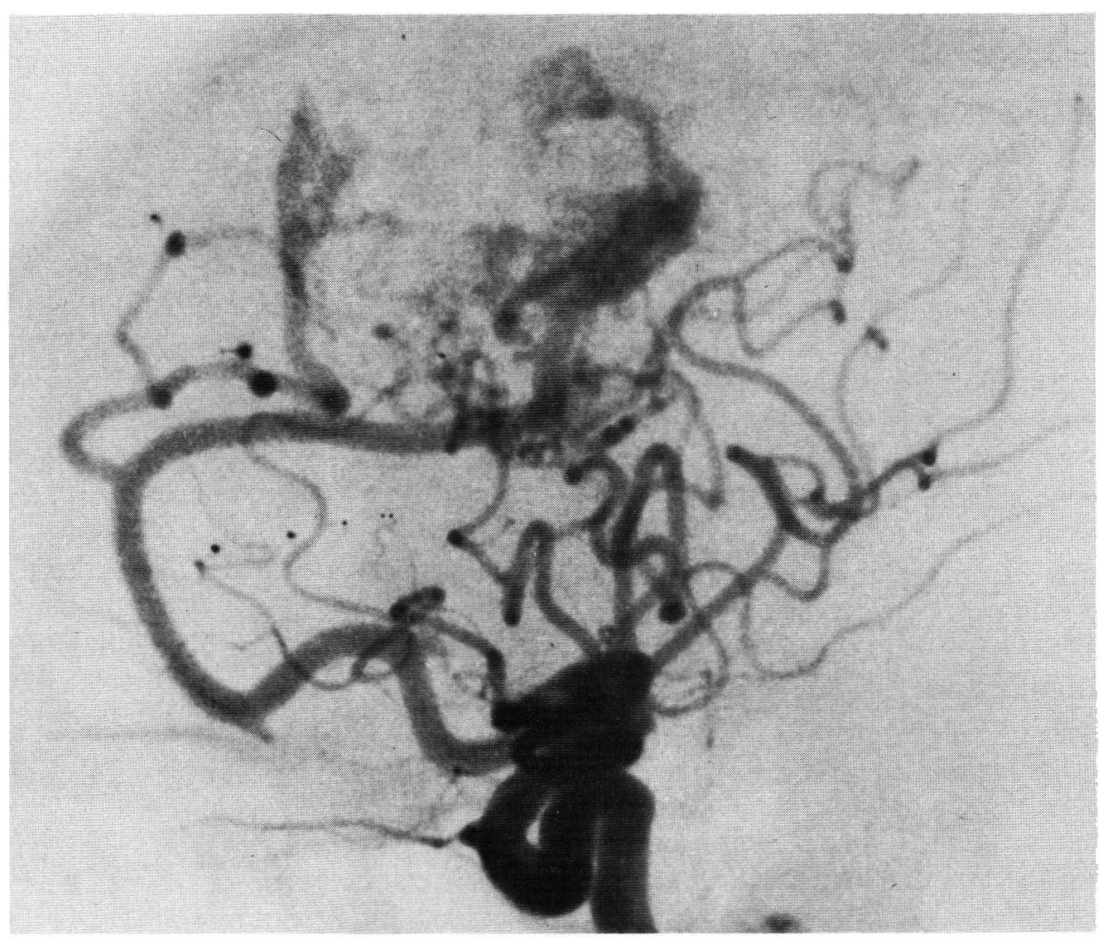

Table 3: CT Findings in 27 Cases of Epilepsy from Cerebral AVMs

\begin{tabular}{lccc}
\hline \hline \multirow{2}{*}{ CT FINDING } & NO. OF CASES & SIZE OF THE AVM \\
& SMALL & LARGE \\
\hline Normal plain CT scan & 4 & 1 & 3 \\
$\quad$ High density lesion without a mass effect & 13 & 2 & 11 \\
$\quad$ High density lesion with a mass effect & 2 & & 2 \\
Low density lesion without a mass effect & 3 & 2 & 1 \\
$\begin{array}{l}\text { Enlarged ipsilateral ventricle } \\
\quad \text { or sylvian fissure }\end{array}$ & 7 & 2 & 5 \\
Diffuse ventricular enlargement & 3 & & 3 \\
Enhancement with infusion & 15 of 19 & 3 of 7 & 12 of 12 \\
Demonstration of an abnormal vessel & 6 of 19 & 0 of 7 & 6 of 12 \\
\hline
\end{tabular}

Table 4: CT Findings in 6 Cases of Angiographically Occult AVMs

\begin{tabular}{|c|c|}
\hline CT FINDING & NO. OF CASES \\
\hline Normal CT scan & 1 \\
\hline High density lesion & 4 \\
\hline Low density lesion & 1 \\
\hline Ipsilateral ventricular enlargement & 1 \\
\hline Ipsilateral ventricular compression & 1 \\
\hline Enhancement with infusion & 2 of 5 \\
\hline
\end{tabular}

as enlargement of the ipsilateral ventricle or Sylvian fissure or as diffuse non-obstructive ventricular enlargement, were seen in ten cases. Vascular enhancement was seen in three of the seven small and in all of the twelve large lesions submitted to CT scanning after intravenous infusion of contrast material. An abnormal blood vessel was demonstrated in six of twelve large lesions following infusion studies (Figure 1).

The non-infused CT scan was abnormal in all but one of the angiographically occult AVMs, and demonstrated a high or low density lesion often interpreted as a glioma. (Table 4). In the sixth angiographically occult case the CT scan also was normal. The small AVM was discovered at the time of histological examination of the temporal lobe removed for the surgical treatment of medically intractable seizures. Vascular enhancement was seen in two of the angiographically occult lesions, thereby demonstrating their vascular nature where angiography had failed to do so.

The diagnosis of AVM was confirmed by histological examination in all sixteen cases operated on. In seven cases, focal areas of hemosiderin deposition were noted in the walls of the abnormal blood vessels, in the parenchyma of the surrounding brain or in associated macrophages; in two of these cases there was other histological evidence suggestive of a remote intracranial hemorrhage. All but two of the angiographically occult AVMs showed extensive thrombosis and focal hemosiderin deposition. 


\section{DISCUSSION}

Most of the lesions in this series were greater than $2 \mathrm{~cm}$ in diameter. This likely reflects the increased probability of hemorrhage from smaller lesions and the tendency of larger ones to present with epilepsy (Gerlach, 1969; Mingrino 1978). Although all patients with a history suggestive of an intracranial hemorrhage were excluded from study, the finding of focal hemosiderin deposition in seven cases raises the possibility of a subclinical or unrecognized intracranial hemorrhage. Other histological evidence suggestive of remote hemorrhage was, however, found in only two of these patients. In the other five, it may be that the focal hemosiderin deposition resulted from diapedesis of red blood cells through abnormally permeable blood vessels. Altered permeability of the abnormal blood vessels of cerebral AVMs, cavernous hemangiomas, and of the blood vessels associated with subacute necrotic myelopathy (FoixAlajouanine syndrome) has recently been demonstrated (Krieger et al, 1982). Three patients with mild negative hemispheric signs and four with atrophic changes on CT scanning had focal hemosiderin deposition. In the other patients with clinical signs and/or with a CT scan suggestive of an atrophic process, these findings may be related to the presence of chronic cerebral ischemia resulting from shunting of blood, within the AVM, away from the adjacent brain. The existence of such a phenomenon accompanying a cerebral AVM, and its reversal with obliteration of the arteriovenous fistula at the time of operation, has been demonstrated by Feindel and co-workers (Feindel et al, 1977). Recently, with positron emission tomography (PET) scanning, it has been possible to identify two groups of AVMs; those with a high shunt flow and regional cerebral "steal" involving the cortex and subcortical zone, and those with minimal or moderate shunting and a periangiomatous steal (Feindel et al, 1981).

There was good correlation between the location of the lesion and the type of seizures encountered. Complex symptoms in the form of rage attacks, feelings of fear and panic and bouts of uncontrollable laughter, however, were seen in three patients with a frontal AVM. In two of these cases simple symptoms and secondary generalization were also seen as part of the clinical picture.

Angiography failed to demonstrate six histologically verified AVMs. In this angiographically occult group, the most common angiographic abnormality was a hypovascular mass. CT scanning was abnormal in all but one of these cases and showed vascular enhancement in 2 of 5 cases thereby demonstrating the vascular nature of the lesions where angiography had failed to do so. The occurrence of angiographically occult AVMs has been recognized with increasing frequency since the advent of CT scanning (Becker, 1979; Bell et al, 1978; Leblanc and Ethier, 1981). Histologically, they often show marked thrombosis and focal hemosiderin deposition (Leblanc and Ethier, 1981).

CT scanning is useful in the investigation of patients with epilepsy. A cerebral arteriovenous malformation is suspected in an epileptic when a high or low density enhancing lesion is associated with signs of cerebral atrophy in the form of enlargement of the ipsilateral ventricle or Sylvian fissure or diffuse ventricular enlargement in the absence of obstruction. This is especially so if an abnormal blood ves- sel is demonstrated with the infusion study. (Figure 1). The CT appearance is helpful in differentiating AVMs from cerebral tumours which often have a mass effect. As previously noted by McRea, however, and as was the case in two of our patients, the angiomatous mass itself can indent the contour of the ipsilateral ventricle (McRea and Valentino, 1958).

A special problem arises in the case of patients with epilepsy from an AVM that has not bled whose angiogram fails to demonstrate a lesion and in whom the CT scan is normal or demonstrates only indirect evidence of an AVM. Operation in these patients is performed for the surgical treatment of medically intractable seizures, the site of operation being determined by our usual criteria. (McNaughton and Rasmussen, 1975). In these cases, the diagnosis of AVM is made postoperatively by the histological examination of the surgical specimen composed of the AVM and associated epileptogenic brain tissue.

Nearly seventy per cent of patients with epilepsy from a cerebral vascular malformation in whom the vascular malformation and associated epileptogenic brain tissue can be excised will remain seizure-free or nearly so (Rasmussen, 1974). At the same time, protection against a future hemorrhage is assured. It is hoped that CT scanning will lead to the earlier diagnosis and treatment of cerebral arteriovenous malformations.

\section{References}

Bauer, G., Pallua, A. (1980) Computerized axial tomography in chronic partial epilepsies. Epilepsia $21: 227-233$.

Becker, D.H., Townsend, J.J., Kramer, R.A., Newton, T.H. (1979) Occult cerebrovascular malformations. A series of 18 histologically verified cases with negative angiography. Brain 102:249-287.

Bell, B.A., Kendall, B.E., Symon, L. (1978) Angiographically occult arteriovenous malformations of the brain. J. Neurol. Neurosurg. Psychiatry 41:1057-1064.

Bogdanoff, B.M., Stafford, C.R., Greene, L., Gonzales, C.F. (1975) Computerized transaxial tomography in the evaluation of patients with focal epilepsy. Neurology 25:1013-1017.

Ethier, R., Sherwin, A., Taylor, S. (1974) Computerized angiotomography: the use of $100 \mathrm{cc}$ of hypaque M-60\%. Clinical and experimental results. Presented at the First International Symposium on Computerized Axial Tomography, Montreal, Canada, May-June.

Feindel, W. (1973) Temporal lobe seizures. In Vinken, P.J. and Bruyn, G.W. (eds): Handbook of Clinical Neurology. The Epilepsies. Vol. 15. Amsterdam, North Holland Publishing Company, pp. 87-106.

Feindel, W. (1975) The influence of cerebral steal. Demonstration of fluorescein angiography and focal cerebral blood flow measurement, in Pia, H.W. Gleaves, E.G., Zierski, J. (eds): Cerebral Angiomas. Advances in Diagnosis and Therapy. Berlin/Heidelberg/New York, Springer-Verlag, pp. 87-99.

Feindel, W., Yamamoto, Y.L., Hodge, C.P., Meyer, E. (1977) Reversal of cerebral steal during surgery of arteriovenous malformations: evidence from fluorescein angiography and focal cortical blood flow measurements. Presented at the 46th Annual Meeting of the American Association of Neurological Surgeons, Toronto, Ontario, April, (Paper no. 12).

Feindel, W., Yamamoto, Y.L., Thompson, C.J., Meyer, E. (1981). Red cerebral veins revisited: cerebral steal in angiomas mapped by positron emission tomography. Presented at the 50th Annual Meeting of the American Association of Neurological Surgeons, Boston, Massachusetts, April, (Paper no. 44).

Gastaut, H., Gastaut, J.L. (1976) Computerized transverse axial tomography in epilepsy. Epilepsia 17:325-336.

Gerlach, J. (1969) Intracranial hemorrhage caused by microangiomas. Prog. Neurol. Surg. 3:363-396.

Hayward, R.D. (1976) Intracranial arteriovenous malformation. Observations after experience with computerized tomography. J. Neurol. Neurosurg. Psychiatry 39:1027-1033.

Jabbari, B., Huott, A.D., Di Chiro, G., Martins, A.N., Youngblood, L.A., Harper, M.G. (1980) Surgically correctable lesions solely detected by $\mathrm{CT}$ scan in adult-onset chronic epilepsy. Ann. Neurol. 7:344-347. 
Kreiger, G., Robitaille, Y., Carpenter, S., Delisle, M.B., Hall, R., Melançon, D. (1982) Sub-acute necrotic myelopathy (Foix-Alajouanine Syndrome): An immunopathological study. Can. J. Neurol. Sci. 9:289 (ABS).

Leblanc, R., Ethier, R. (1981) The computerized tomographic appearance of angiographically occult arteriovenous malformations of the brain. Can. J. Neurol. Sci. 8:8-13.

Leblanc, R., Ethier, R. Little, J.R. (1979) Computerized tomography findings in arteriovenous malformations of the brain. J. Neurosurg. 51:765-772.

Loiseau, P., Caille, J.M., Jallon, P., Constant, P. (1977) Encephalotomographie axiale transverse traitée par ordinateur dans les épilepsies partielles. Rev. Neurol. (Paris) 133:31-34.

McNaughton, F.L., Rasmussen, T. (1975) Criteria for the selection of patients for neurosurgical treatment. In: Purpura, D.P., Penry, J.K., and Walter, R.D. (eds). Advances in Neurology, volume 8: Neurosurgical Management of the Epilepsies. Raven Press, New York, pp. 37-48.

McRea, D.L., Valentino, V. (1958) Pneumographic findings in angiomas of the brain. Acta Radiol. (Stockh) 50:18-26.

McGahan, J.P., Dublin, A.B., Hill, R.P. (1979) The evaluation of seizure disorders by computerized tomography. J. Neurosurg. 50:328-332.
Meese, W., Aurlich, A., Kazner, E., Wullenweber, R. (1976) CT findings in angiomas and aneurysms, in Lanksch, W., Kazner, E. (eds): Cranial Computerized Tomography. Berlin/Heidelberg/New York, Springer-Verlag, pp. 291-297.

Mingrino, S. (1978). Supratentorial arteriovenous malformations of the brain. In: Krayenbuhl, H. (ed). Advances and Technical Standards in Neurosurgery, Vol. 5, New York, Springer-Verlag, pp. 105-123.

Pressman, B.D., Kirkwood, R.J., Davis, D.O. (1975) Computerized transverse tomography. In: Vascular lesions of the brain. Part l. Arteriovenous malformations. Am. J. Roentgenol. 124:208-214.

Rasmussen, T. (1974) Surgery of epilepsy associated with brain tumors. In: Purpura, D.P., Penry, J.K., Walter, R.D. (eds): Advances in Neurology, Vol. 8: Neurosurgical Management of the Epilepsies. New York, Raven Press. pp. 227.239.

Scollo-Lavizzari, G., Eichhorn, K. Wuthrich, R. (1977) Computerized transverse axial tomography (CTAT) in the diagnosis of epilepsy. Eur. Neurol. 15:5-8.

Terbrugge, K., Scotti, G., Ethier, R. (1977) Computed tomography in intracranial arteriovenous malformations. Radiology 122:703-705. 